\title{
Manufactured Maladies: Lives and Livelihoods of Migrant Workers During COVID-19 Lockdown in India
}

\author{
Anindita Adhikari ${ }^{1}$ - Navmee Goregaonkar ${ }^{2}$. Rajendran Narayanan ${ }^{3,4}$. \\ Nishant Panicker ${ }^{3}$. Nithya Ramamoorthy ${ }^{5}$
}

Accepted: 2 September 2020 / Published online: 21 October 2020

(c) Indian Society of Labour Economics 2020

\begin{abstract}
The 68 days of lockdown in India, as a measure to contain the spread of the COVID19 pandemic, resulted in an unprecedented humanitarian crisis, unlike any other in the world. In the first half of the lockdown, migrant workers were stranded with no food and money with severe restrictions on movement when a mass exodus of workers back to their hometowns and villages began. In the second half, the workers' woes were compounded with a series of chaotic travel orders and gross mismanagement of the repatriation process. In this article, we draw on the work of Stranded Workers Action Network (SWAN) with more analysis and perspective. SWAN was a spontaneous relief effort that emerged soon after the lockdown was announced in March 2020. In addition to providing relief, SWAN concurrently documented the experiences of over 36,000 workers through the lockdown. We highlight the inadequacy of the government and judicial response to the migrant worker crisis. We present quantitative data elaborating the profile of workers that reached out to SWAN, the extent of hunger, loss of livelihoods and income. We also present qualitative insights based on interactions with workers and discuss multiple, non-exhaustive, dimensions of vulnerability to which migrant workers were exposed.
\end{abstract}

Keywords COVID-19 $\cdot$ Migrants $\cdot$ Labour $\cdot$ Lockdown $\cdot$ India $\cdot$ Inequality

\footnotetext{
All the authors are SWAN volunteers. However, this article is not a SWAN initiative and hence does not reflect the views of SWAN as a platform. Names of all the workers in this article have been changed for the sake of privacy.
}

Rajendran Narayanan

rajendran.narayanan@apu.edu.in

Extended author information available on the last page of the article 


\section{Introduction}

The first COVID-19 positive case in India was reported in Kerala, India, on 30 January 2020. A few hours later, the World Health Organisation (WHO) announced the novel coronavirus to be a 'global health emergency'. However, the Ministry of Health and Family Welfare did not launch its COVID-19 awareness campaigns till 6 March 2020 (Sen 2020). Without any prior intimation or public consultation, on 24 March 2020, the Prime Minister of India, Narendra Modi, from a pulpit behind a camera announced a nationwide lockdown giving just four hours' notice to the country. This caught millions of people-including the state governments and the bureaucracy-off-guard leaving them no time to plan for such an emergency. While the lockdown did not contain the spread of the virus as expected, it did spawn a humanitarian crisis of epic proportions. India's lockdown has been cited as one of the most 'stringent' and 'stingy" lockdowns in the world shutting down the economy and movement with a meagre fiscal package for the vulnerable (Hale et al. 2020).

Originally meant for 21 days, the lockdown underwent extensions lasting well into May and June with the easing of some restrictions. The footloose, migrant workers, already living on the precipice of dignified existence, arguably bore the maximum brunt of this decision. The sudden lockdown caused much panic among migrants who lost their employment overnight with neither any income nor any food security. The panic caused millions of migrant workers to walk hundreds of miles in a quest to go home. The tragic scenes were reminiscent of mass movement during the Great Depression as in John Steinbeck's novel The Grapes of Wrath or as in the post-partition mass movement closer home. Many migrants successfully reached their home states only to be quarantined in camps. Thousands were subject to brutality. Several millions were stranded far from home, with no money or food.

As the exodus of migrants walking home began to flood TV screens, the Government of India's (GoI) and the Supreme Court's (SC) apathy, disconnect with the working poor and wilful neglect of justice became apparent. Two public interest litigations filed in the SC to respond to the crisis with immediate food and cash relief were quashed. The GoI passively watched the crisis unfold for nearly 50 days and made its first announcement for migrants on 14 May 2020. The first fiscal package announced 2 days after the lockdown did not have any specific measures for migrants. First, migrant workers stranded away from their homes were not eligible to access ration shops and the 'free foodgrain' announced by the GoI in the places where they were stranded. Second, while there was an announcement of some cash support for construction workers, in reality, more than two-thirds of construction workers are not registered and hence not even eligible to receive any cash support.

The SC disposed of the petition for wages for migrant workers because they were satisfied with the government's efforts and made a statement which will not be easily forgotten-'if they are being provided food then why do they need money for

\footnotetext{
${ }^{1}$ https://www.economist.com/finance-and-economics/2020/04/04/emerging-market-lockdowns-match -rich-world-ones-the-handouts-do-not.
} 
meals'. The only concrete measure taken by the GoI to respond to migrant worker distress at that time was the provision of cooked meals to 1.5 million people in shelters across the country. The number was a mere fraction of the 80 million figure cited by the Finance Minister (FM) herself, when she announced the provision of free food grains through the Public Distribution System (PDS) to migrant workers on 14 May 2020. Even subsequent announcements for extending the provision of PDS grain for three months and an employment programme in select districts of the country were made at the end of the June 2020, well after a catastrophic toll on the lives and livelihoods of people.

In the first half of the lockdown, migrant workers were coerced to be stranded with no food and money. In the second half, the workers' woes were compounded with a series of chaotic travel orders and gross mismanagement of the repatriation process. From April end, eight travel related orders were issued by the Ministry of Home Affairs (MHA) in one month, each one as vague as the other. The travel procedures were opaque and ill-defined. The trains being scheduled were inadequate and ill-planned thereby amplifying the woes of the stranded migrants (SWAN 2020c). On 25 May 2020, in an attempt to restore faith in the judiciary, 20 senior SC advocates wrote a letter to the CJI and other senior judges of the SC seeking cognizance of the biggest humanitarian crisis in independent India. It took a mix of grim statistics, large-scale deaths, deplorable images on the television, among others for the SC to finally wake up. The SC took suo moto cognizance of the situation on 28 May 2020 and started hearings, but these were primarily focused on arrangements for migrant travel. Compliance reports from various state governments on the transport and registration of migrant are yet to be submitted at the time of writing this article. ${ }^{2}$ In the meanwhile, the SC has declared that the Prime Minister's Citizen Assistance and Relief in Emergency Situations (PM-CARES) fund, created specifically for donations for relief during the COVID crisis, will not be subject to public scrutiny.

As per data collated and maintained by four people-Aman, Kanika Sharma, Krushna R, and Thejesh G.N.- at least 972 have died not due to COVID. Starvation, exhaustion and accidents during travel, lack of medical care, police brutality and suicides ${ }^{3}$ will mark the 68-day lockdown as one of the darkest periods of State failure in India's history. For a longer discussion on the GoI's inadequate economic response to the crisis created by the unplanned lockdown, see Ghosh (2020) and Ray and Subramanian (2020).

The crisis jarringly brought to the fore how the Indian State has routinely neglected fundamental questions regarding social protection measures in a society with toxic levels of socio-economic inequality. The plight of the migrant workers must be seen as a brutal consequence of a widening inequality over the last three decades coupled with the crisis of unemployment (under-employment), low income and consumption.

\footnotetext{
${ }^{2}$ https://scroll.in/latest/969087/migrant-crisis-supreme-court-gives-states-3-weeks-to-file-replies-oncompliance-of-its-orders.

3 Full dataset: https://thejeshgn.com/projects/covid19-india/non-virus-deaths/.
} 
There is much to celebrate in terms of several progressive rights-based legislations and redistributive policies, especially in the first decade of this millennium. But, widening economic inequality has been a concern. Reduction in poverty and reduction in precarity have been much slower compared to the cited story of growth (Sen and Himanshu 2004). This was also marked by regional imbalances. The already rich states got richer, and the poor states became poorer (Deaton and Drèze 2002). Interstate migration for work is largely concentrated in urban areas, and urban inequality has been a main driver of overall inequality. Occupational continuities of the urban poor point to a chronic nature and reproduction of the gap between the urban elites and the urban workers (Jayadev et al. 2007; Vakulabharanam and Motiram 2012). This is even more alarming as $86 \%$ of the Indian economy is driven by the informal workforce that contributes an estimated $50 \%$ of the GDP (NCEUS 2008). The rural-urban migration showed a significant increase in the first decade of the millennium (Srivastava 2011). With stagnating rural wages and an intentional under-funding of the National Rural Employment Guarantee Act (NREGA), the rural-urban migration appears to continue. The Indian Economic Survey 2017 estimates that there are roughly 9 million interstate migrants each year between 2011 and 2016 (Sharma 2017). Widening inequality of wealth and income is also correlated with unequal access to basic services such as health, education and other social protection measures. Owing to some structural inequalities specific to India, historically marginalised communities like Muslims, Dalits, Adivasis and women are disproportionately affected in access to wealth (Himanshu 2018). While SWAN did not explicitly collect identity-based information from the migrants, anecdotal evidence suggests that marginalised communities were hit the hardest due to a systemic shock such as lockdown.

A second ingredient—in addition to widening inequality - that has heightened the hunger and livelihoods crisis is the steady slowdown of the Indian economy. The Indian economy was slowing well before the onset of the pandemic. While the GDP in India had been growing between $6 \%$ and $7 \%$ in the last two decades, the employment growth had been less than 1\% (State of Working India 2018). Decreased demand, particularly severe in rural areas, has contributed to this slowdown and unemployment. Even the government's Consumption Expenditure Survey (CES) and the Periodic Labour Force Survey (PLFS) (Government of India, Ministry of Statistics and Programme Implementation 2020), among several other reports point to this.

The GoI suppressed the release of the most recent CES data. According to the report, leaked to and published by the Business Standard (Jha 2019), consumer spending fell for the first time in 40 years. The monthly per capita consumption expenditure (MPCE) has decreased uniformly across rural India between 2011-12 and 2017-18 (Subramanian 2019). This reduced capacity to spend is closely related to lack of employment and low income.

There has also been much debate surrounding the absolute numbers of the workforce in India.

A comparison of the estimates of the workforce by various studies is presented in Nath and Basole (2020). These authors estimate that the workforce for 2017-18 
is between 439.2 million and 452.4 million based on the chosen definition of employment.

The PLFS data of 2018-19, released in June 2020, provide employment information prior to 24 March 2020. Statistics in PLFS 2018-19 are similar to PLFS 2017-18. As per these reports, roughly half of the working age population is either not employed or not seeking work. It is worrying that there is a $7 \%$ decline in the Labour Force Participation Rate (LFPR) between 2011-12 and 2017-18 for those more than 30 years old (Kapoor 2019). While regular, salaried work is universally preferable over casual labour, even they have not been paid well (Thampi and Anand 2019). ${ }^{4}$

In this article, we will draw on the work of a spontaneous relief effort that emerged soon after the lockdown, the Stranded Workers Action Network (SWAN). All five authors are volunteers with SWAN and were actively involved in providing relief and concurrently documenting the experiences of 3904 worker groups adding up to 36,343 workers through the lockdown period.

In Section 2, we discuss SWAN's intervention and methodology of documenting the crisis. In Section 3, we discuss the profile of migrant workers who reached out to SWAN. We present the main quantitative insights in Section 4. In Section 5, we delve into the qualitative information collected by volunteers and present a nonexhaustive set outlining the severity of vulnerability followed by a brief Discussion in Section 6.

\section{SWAN's Intervention and Data}

The first request for relief for stranded migrant workers came from Sanjay Sahni, an activist and founder of Samaj Parivartan Shakti Sangathan (SPSS), from Muzaffarpur, Bihar. Sanjay sought financial assistance for a group of workers stranded in Karnataka. Soon, many migrant workers connected to SPSS started reaching out to Sanjay for support. In turn, Sanjay reached out to some friends (who would later form SWAN) for food and cash assistance. Sanjay started vetting the distress messages before routing them to SWAN. As the frequency of such distress calls and messages rapidly increased, the informal network of friends engaged in relief work started a helpline platform and called it SWAN. The members simultaneously created appeals for funds and volunteers for relief work.

With mounting distress calls, zonal volunteer teams were formed and each zonal team worked in shifts. Soon, SWAN started proactively picking up distress messages from various WhatsApp groups and other social media platforms. Very basic information such as the name and contact details of a stranded worker obtained from these channels were logged in a spreadsheet. The respective zonal teams then picked these up, followed up with a call with the concerned worker and assessed the

\footnotetext{
4 Around $45 \%$ of the regular workers earned less than Rs 10,000 a month and about $72 \%$ of the regular workers earned less than the minimum wages of Rs 18,000 per month prescribed by the 7 th pay commission.
} 


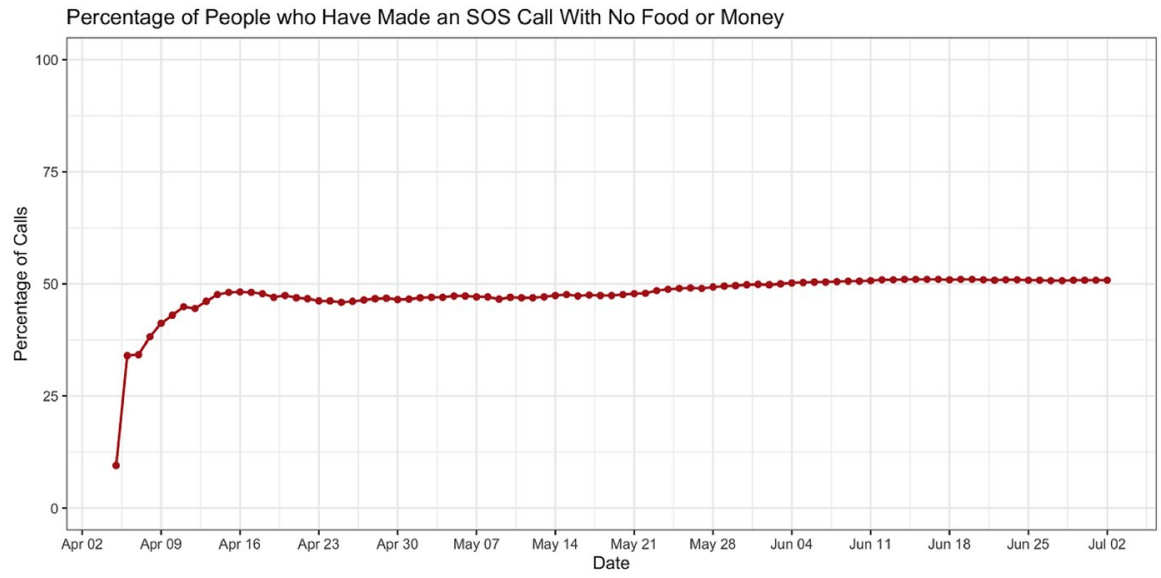

Fig. 1 Percentage of SOS calls over time. Source: Data Collected by SWAN team

needs of the stranded workers based on a standardised form. Assessment of needs meant collecting the following information from workers: the group size, number of women and children, precise location of where they were stranded, home state, number of days of rations left, amount of money left, if they received rations or cooked food from the government, if they were paid during the lockdown and a comments section where volunteers noted other relevant details. Relief work primarily consisted of connecting stranded workers with civil society organisations (CSO) and attempts to have government rations reach them. The volunteer making the call then consulted a list of responsive government representatives and CSOs and notified them about the need for food supplies of the stranded worker group. While government response in most places was patchy, many CSOs rose to the occasion and arranged for food supplies to reach the stranded. However, it became clear that it was easier for both the government and CSOs to cater to large stranded worker groups. For smaller groups therefore, SWAN facilitated small direct cash transfers into their accounts to buy rations and essentials for a week at a time. Between 27 March 2020 and 3 July 2020, a total of around Rs 6 million was transferred directly to the workers' accounts through crowdsourced funds.

While quantitative data help us understand the scale of problems, they tend to convey a limited story. SWAN volunteers also documented issues based on free flowing conversations with workers. Any attempts at quantifying these would be reductive. These conversations have been a vital source for SWAN to assess the different dimensions and depth of vulnerability and helped the volunteers to designate specific calls as SOS. In particular, when workers indicated that they were left with no money and less than one day of rations, the volunteers categorised the call as an SOS. Figure 1 shows that throughout the lockdown period, almost $50 \%$ of the calls received were SOS indicating the precarious conditions that the Indian State pushed the workers into. As distress calls increased, volunteers became more stringent in designating a case as SOS owing to limited resources available to SWAN. Consequently, Fig. 1 shows a conservative estimate. 


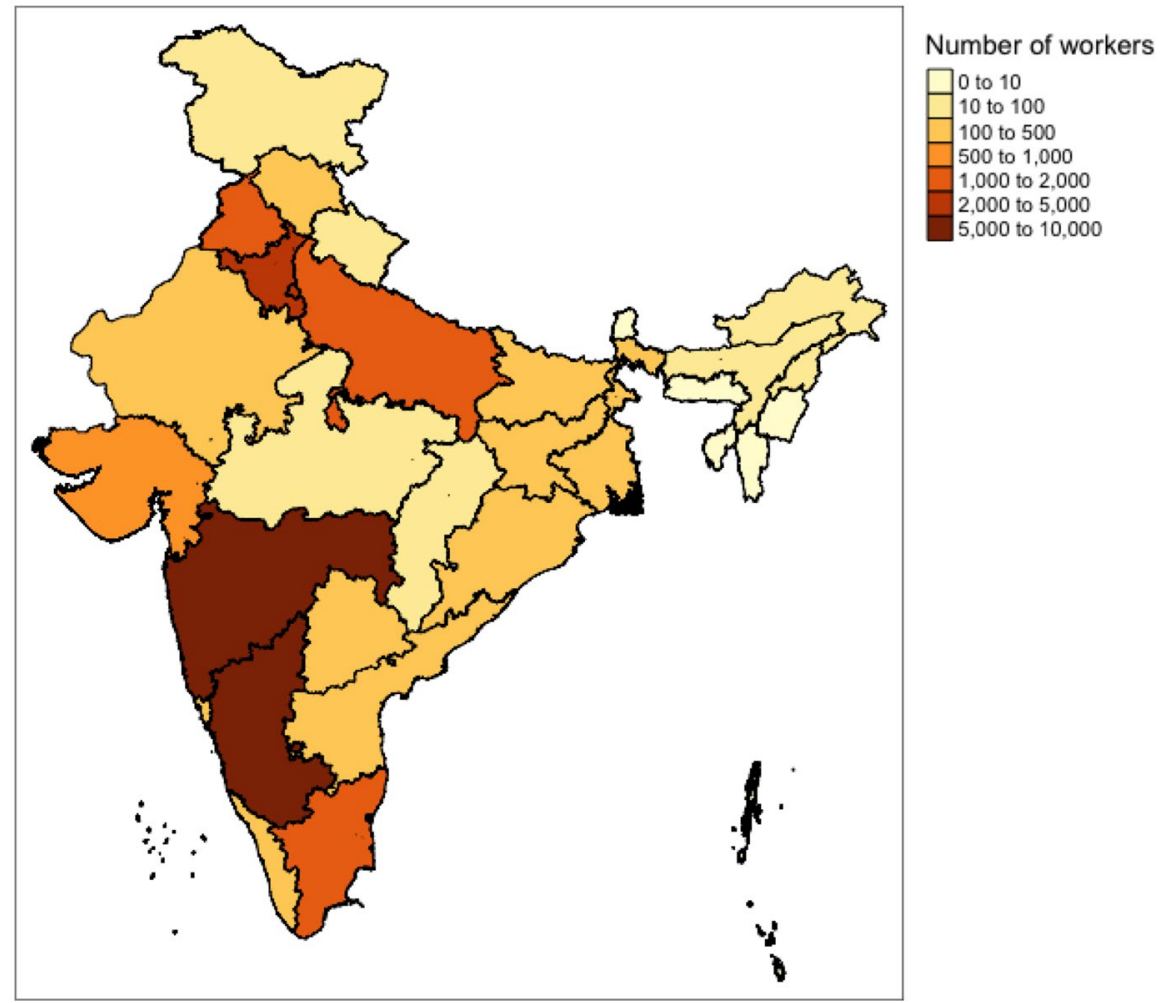

Fig. 2 Distribution of stranded workers based on distress calls. Source: Data Collected by SWAN team

Early into the relief efforts, SWAN volunteers realised that direct help can only be extended to a fraction of migrant workers as the scale of the crisis was much larger. So it was decided that the information being collected real-time would be used to amplify the voices of workers to advocate for the urgent expansion of government relief. To this end, SWAN released three reports between April 2020 and June 2020 (SWAN $2020 \mathrm{a}, \mathrm{b}, \mathrm{c})$. Each report builds on earlier ones and documents the changing nature of distress over the lockdown period. For more on SWAN, the reader is referred to the three SWAN reports and numerous media reports such as Katakam (2020). 
Table 1 Number of stranded workers based on employment category, their median daily earnings

\begin{tabular}{lcc}
\hline Employment category & Number of workers & $\begin{array}{l}\text { Median daily } \\
\text { earnings (₹) }\end{array}$ \\
\hline Factory/company/construction work & 15,648 & 365 \\
Self-employed & 5449 & 385 \\
Non-group-based employment & 2367 & 308 \\
Other & 3881 & 350 \\
Unemployed & 7 & 0 \\
\hline
\end{tabular}

Source: Data Collected by SWAN team

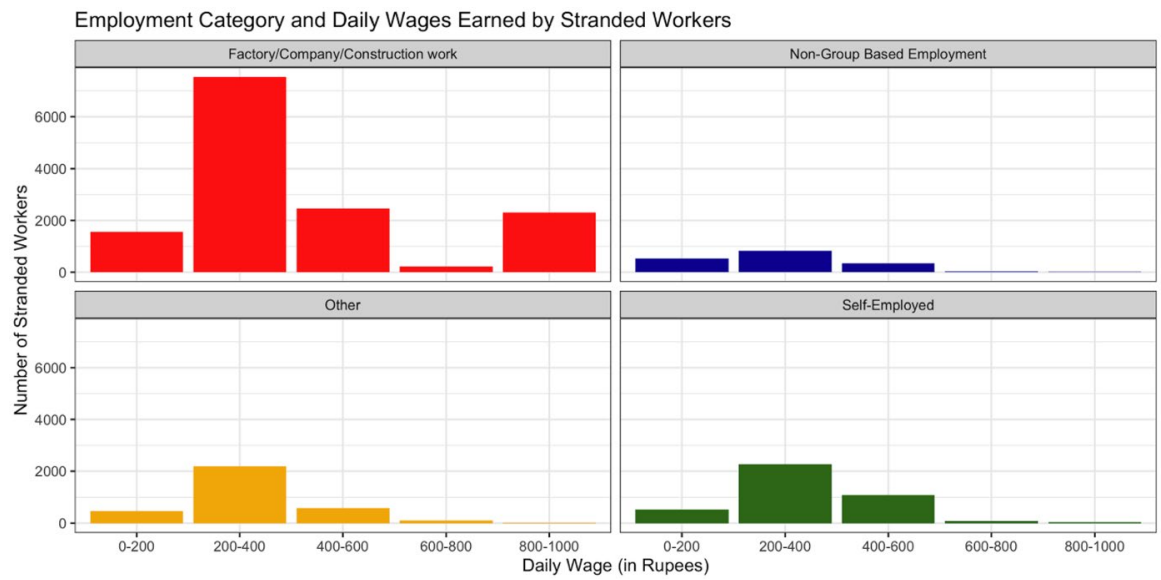

Fig. 3 Distribution of daily wages by employment category before lockdown. Source: Data Collected by SWAN team

\section{Profile of Workers}

Each distress call that SWAN received corresponded to a group of stranded workers. The data pertaining to availability of rations and money in this article are under the assumption that the situation is true for the group that the caller represents. We acknowledge that there could be variations in the amount of money left with different workers in the group but food insecurity would hold true for the whole group. These are not based on a purposive, designed survey but based on information collected for providing temporary relief. Consequently, the usage of the word 'sample' is only for ease of presentation. The group sizes varied from 1 to 500. In our analysis, we have excluded group sizes exceeding $550 .^{5}$

\footnotetext{
$\overline{5}$ For groups above 550 people, it was felt that individual calls cannot be considered as representative of the entire group. This number was arbitrarily chosen based on experience. Also, for the groups that exceeded 550 people, we either did not have sufficient data or the respondents claimed to be selfemployed, which would skew the analyses.
} 
Table 2 Distribution of kind of wages by employment category

\begin{tabular}{lccc}
\hline Employment category & Daily wage earners & $\begin{array}{l}\text { Weekly wage } \\
\text { earners }\end{array}$ & $\begin{array}{l}\text { Monthly } \\
\text { wage earn- } \\
\text { ers }\end{array}$ \\
\hline Factory/company/construction work & 7442 & 5360 & 1037 \\
Self-employed & 2409 & 998 & 485 \\
Non-group-based employment & 703 & 959 & 45 \\
Other & 1264 & 983 & 298 \\
\hline
\end{tabular}

Source: Data Collected by SWAN team

Number of workers different from Table 3.2 since not all workers responded to the question we asked regarding the nature of wages they received

Figure 2 shows the distribution of stranded workers based on distress calls. The majority of the migrants who reached out to SWAN were concentrated in Maharashtra and Karnataka, followed by Delhi and Haryana. The highest concentration of stranded workers were in Mumbai and in Bangalore. Workers were engaged in an array of employment types. This included various kinds of factory workers, construction workers, street vendors, drivers, domestic helps, zari workers etc. To standardise the assessment of needs of workers, we created four broad categories of the nature of employment. Table 1 summarises the number of workers in each category and the median daily income of this category of workers prior to the lockdown as reported to SWAN. Figure 3 shows the distribution of workers by their employment category and the corresponding daily wages that they earned before lockdown. Source: Data Collected by SWAN team

We now attempt to compare the worker profile in our sample with nationally representative statistical estimates. As per PLFS 2018-19, about $42.8 \%$ of the urban households earned a regular wage/salary (RWS) and about $31.8 \%$ of urban households were self-employed. Roughly $11 \%$ of the urban households depended on casual labour. The average daily income for RWS employees ranges from Rs 726 to Rs 750 for men. For women workers in urban areas, this ranged from Rs 554 to Rs $604 .^{6}$ The average daily income for men engaged in casual labour other than public works in urban areas ranged from Rs 342 to Rs 368, while it was between Rs 205 and Rs 244 for women. For RWS formal workers, the average daily income exceeds Rs 1102, and for RWS informal workers, the average daily income is around Rs 400. The average daily income for the self-employed is Rs 560 (Kapoor 2020).

In our sample of workers, about $57 \%$ were factory/construction workers, about $8.65 \%$ belonged to the non-group-based employed category, and about $20 \%$ were self-employed. Based on the income reported by the workers, it appears reasonable to assume that a significant majority of them were RWS informal workers and casual labourers. Using this categorisation, roughly $65.8 \%$ of those who reached out belong

\footnotetext{
${ }^{6}$ Based on the Current Weekly Status (CWS) and 26 days work in a month.
} 
to this category. This is obtained by combining the SWAN categories of factory/construction workers and the non-group-based employment. Some contractors reached out whose incomes were higher than the RWS informal and casual labour as indicated in the tail of the distribution in Fig. 3.

In Table 2, we show the distribution of daily, weekly, and monthly wage earners by employment category. A large majority of daily wage earners in our sample also indicates predominance of RWS informal and casual workers.

\subsection{Long-Term Migrants and Recent Migrants}

A majority of distress calls were from short-term interstate migrants. Over a period of time, distress calls from longer-term migrants or 'settled population' and intrastate migrants increased. This indicates a widening net of vulnerability. This is also corroborated by the surveys of Gramvaani (2020a, b). We first present two cases of long-term settled migrants based on calls to SWAN.

Sabeena was a long-term resident of Davangere, Karnataka. She had dependent children and a paralysed husband. She had neither been paid her daily wages of Rs 250 nor received any government assistance during lockdown. She needed money for medicines and provisions for the family. Azad Prasad was part of a group of 7 members from Bihar who had been residents of Delhi for several years. Azad worked in a small shop and earned Rs 400 per day but had not been paid during lockdown. He, however, had to pay house rent of Rs 4500. They had run out of cooking gas, and his children had trouble eating at the government feeding centres. He reached out to SWAN on May 14 at a time when he had no money left and had just one day of rations remaining.

While long-term migrants and the so-called settled population might still have some social network to tap into for essentials, it is not the case for new migrants. This is also affirmed by a recent study that finds that local political representatives in urban areas are less likely to respond to requests for public services when they come from recent migrants to the city instead of long-term residents (Gaikwad and Nellis 2020). While we do not have precise estimates of how many among those who reached out were recent migrants, we do, however, present a few cases here to illustrate their nature of precarity.

Naseer Ahmed had migrated to Bangalore from Assam in January 2020. He was a construction worker and lived in a kutcha house with three others that included children. While he earned Rs 300 per day before the lockdown, the contractor had not kept in touch with him since the lockdown, so his wages were pending. In his call, he repeated multiple times that they were new to the city and that they do not know how to get help or resources from anywhere. Some of them were forced to ask for money to be sent from home for their survival. While this was fairly common among stranded students, this was also true for workers such as Ramesh Kumar, who had reached Delhi from Bihar just after lockdown, and had to rely on his mother to send money, while she herself managed a household with a sick husband. When state borders opened up, such cases became more common, with people borrowing large amounts or even selling possessions to fund their relatives' travel home. In many 


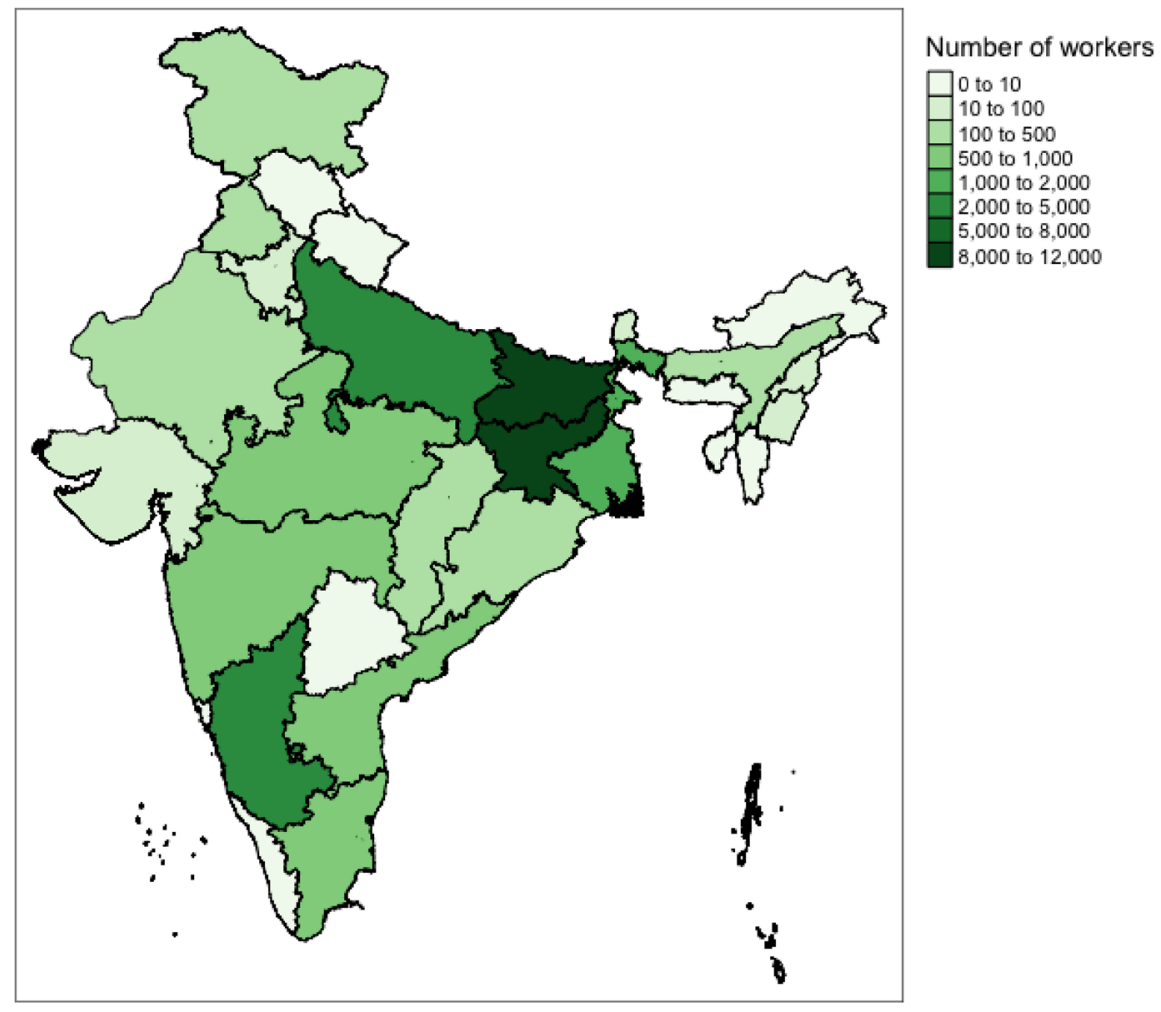

Fig. 4 Origin states of workers. Source: Data Collected by SWAN team

cases, migrant workers who were in need of monetary help did not have their passbook and bank details with them. As a result, volunteers had to look for alternate forms of relief for them.

Along with his wife and kids, Mahesh Kumar had moved to Noida, Uttar Pradesh, from Bihar just a week before lockdown. He was supposed to earn Rs 5500 per month to work in a factory. Having worked for just 4 days, he was denied wages by the company. He had not received any rations from the government and neither he nor his wife had received any cash transfer from the state or central governments. Since he also had to pay house rent for the duration, he sought travel assistance to go home.

An added layer of complexity for migrants from the rest of India to the south of India was linguistic differences. This created more hurdles in accessing information about government food centres and any other government aided support. A public health emergency was also not immune to religious discrimination. There were numerous instances when Muslim migrants were discriminated against. In fact, in several cases, they were denied access to relief not only by the government, but also by their neighbours, landlords and employers. Moreover, owing to the aftereffects of the Delhi communal riots, along with the pandemic, made it extremely difficult for some migrant workers to sustain during the lockdown. 


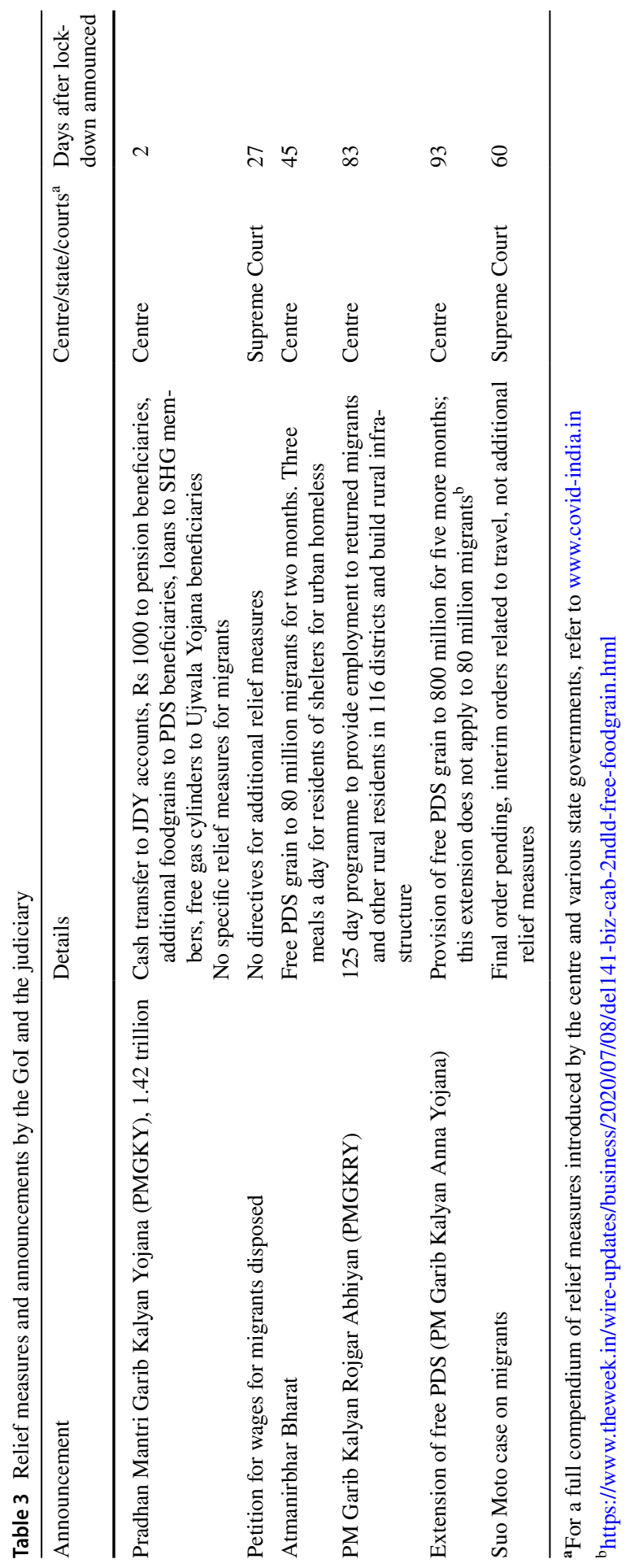




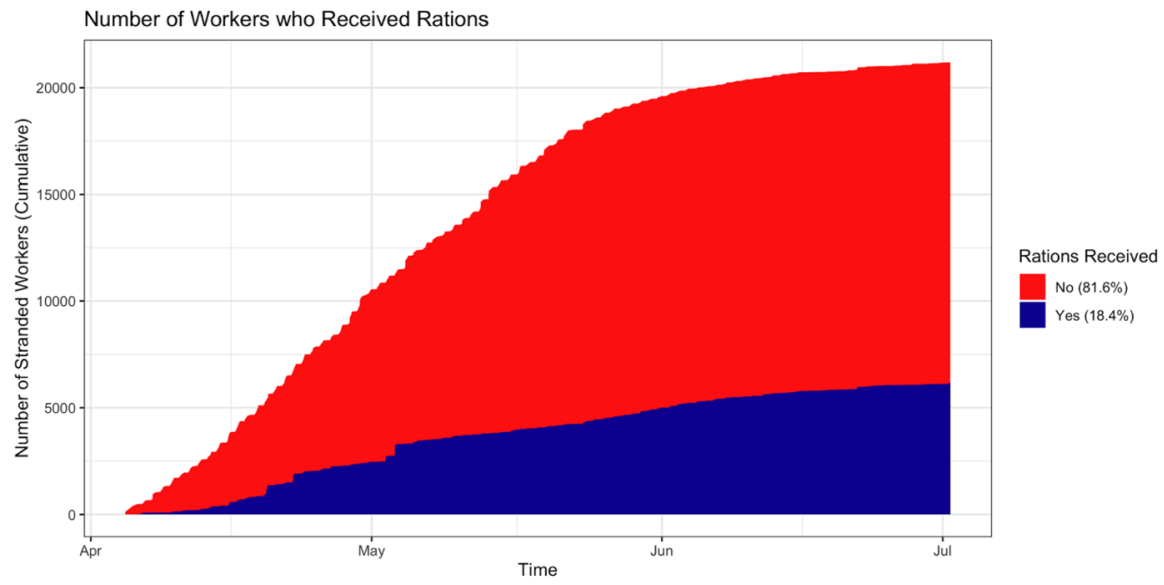

Fig. 5 Number of stranded workers who received rations throughout the lockdown. Source: Data Collected by SWAN team

Figure 4 shows the distribution of the state of origin of the stranded workers. Most of the workers who reached out were from Bihar, followed by Jharkhand, Uttar Pradesh, internal migrants from Karnataka stranded in cities such as Bangalore and Mangalore, and West Bengal.

While short-term migrants relied more on their own savings for food and other needs, resident workers, despite being settled, were more likely to sell their assets for survival. Regardless, both groups largely depended on borrowings for survival (Gramvaani 2020a, b). This further highlights the lack of any social network and hostility that kept reinforcing their 'outsider' status. This yet again calls into question the fundamentals of federalism, constitutional guarantees and citizenship.

\section{Access to Food and Cash}

The second SWAN report (SWAN 2020b) includes a detailed timeline marking important announcements by the GoI in response to the pandemic till 1 May 2020. The third SWAN report discusses government orders pertaining to travel (SWAN 2020c). We present an abridged version of announcements from the start of the lockdown (summarised in Table 3), highlighting whether or not migrant workers were able to access these benefits. 


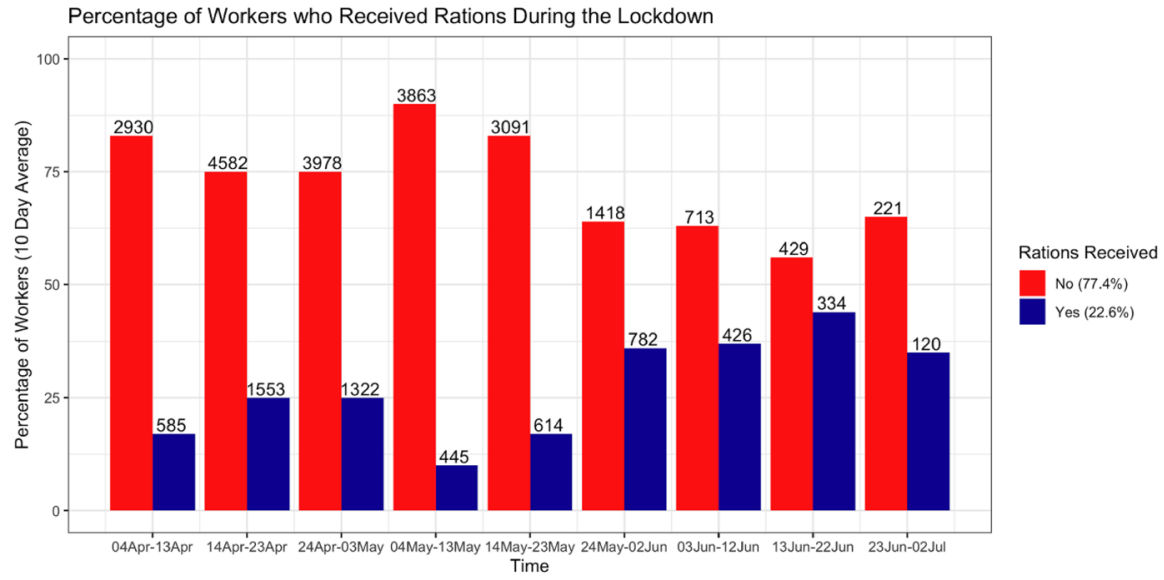

Fig. 6 Percentage of workers who received rations during the lockdown, calculated using a ten-day average. Source: Data Collected by SWAN team

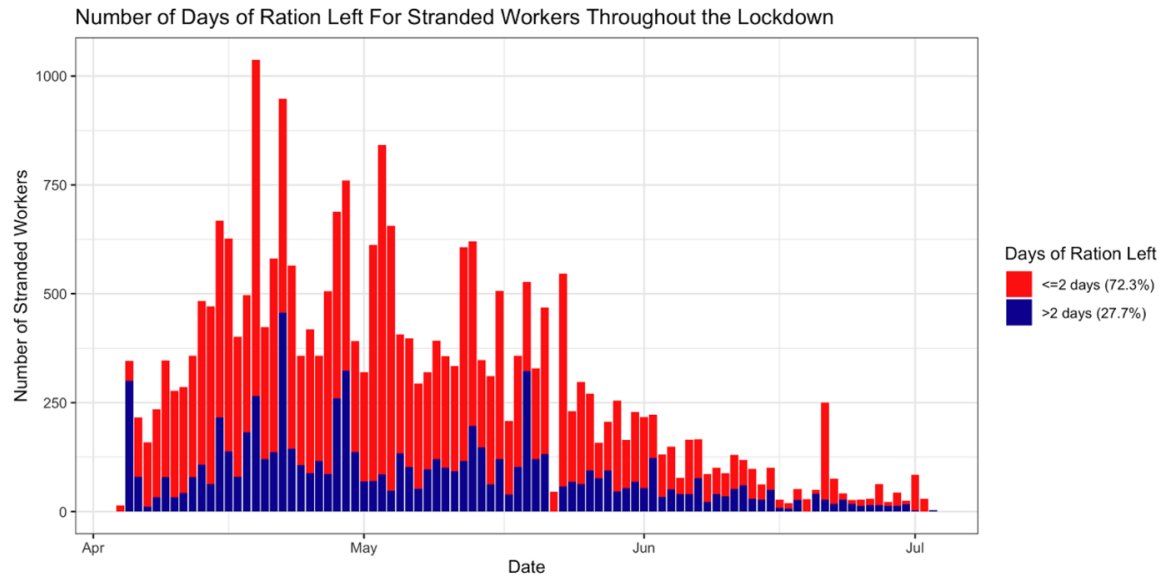

Fig. 7 Number of days of rations left for stranded workers throughout the lockdown. Source: Data Collected by SWAN team

\subsection{Rations and Cooked Food}

According to the 2019 Global Hunger Index, ${ }^{7}$ India ranks 102 out of 117 countries. This is based on data collected between 2014 and 2018. Many countries in sub-Saharan Africa are ranked higher. Considering claims of high growth, this is a shameful statistic pointing to extreme inequalities. As remarked by Drèze and Sen (2013), one is indeed reminded of India being akin to 'pockets of California in subSaharan Africa'.

\footnotetext{
7 https://www.globalhungerindex.org/results.html.
} 


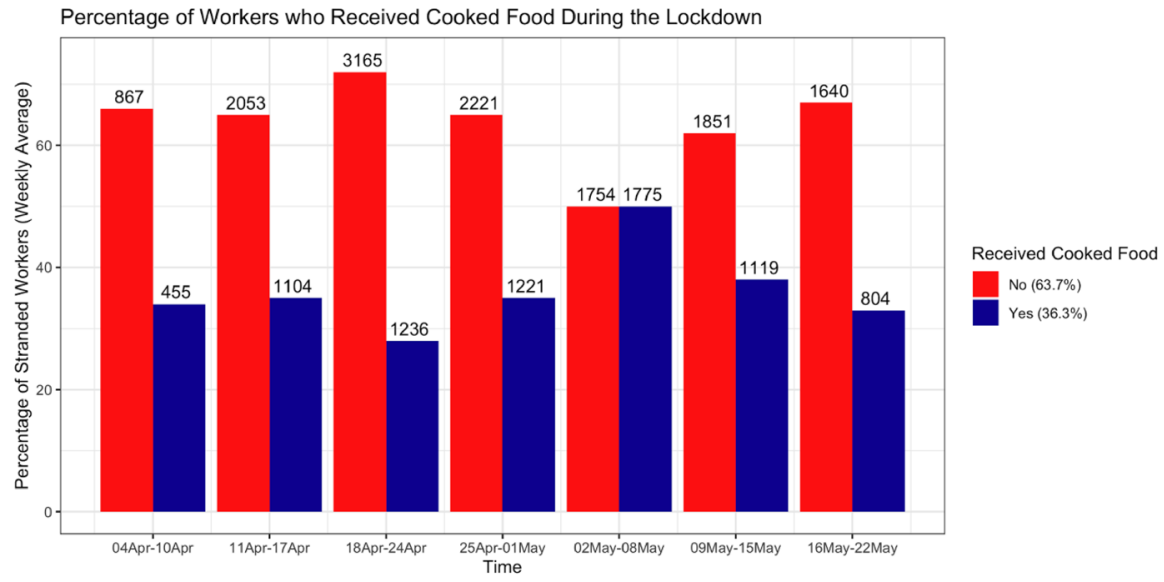

Fig. 8 Weekly average percentage of people with access to cooked food over time. Source: Data Collected by SWAN team

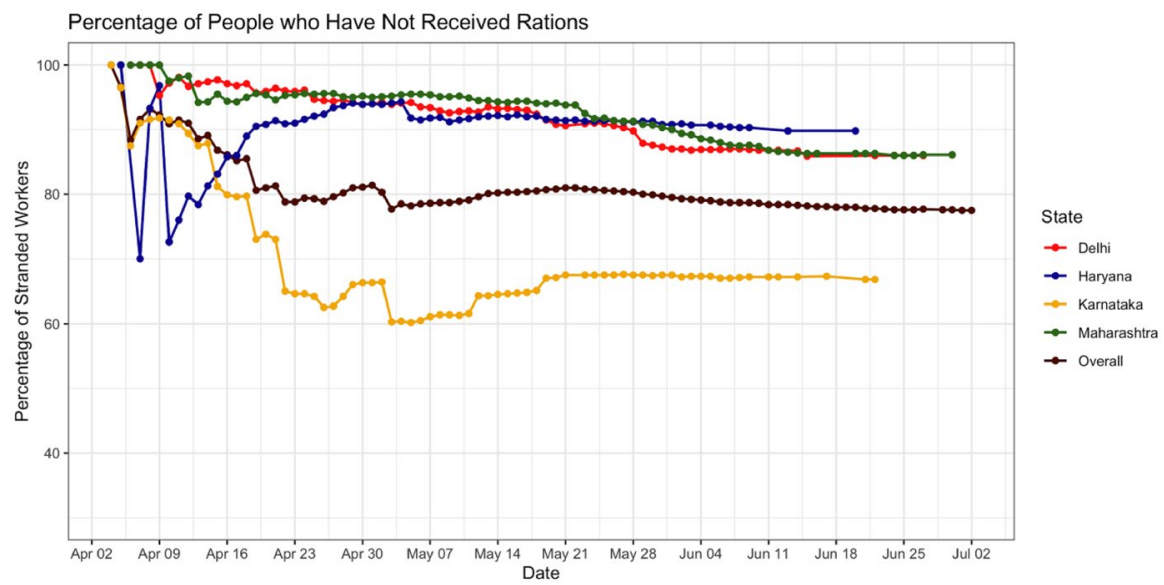

Fig. 9 Percentage of people who did not receive rations over time. Source: Data Collected by SWAN team

The PDS is part of the National Food Security Act (NFSA). Roughly 67\% of India's population is entitled to subsidised food grains through NFSA. According to recent estimates by Jean Drèze, Reetika Khera and Meghana Mungikar ${ }^{8}$ more than 100 million people are excluded from their PDS entitlement because the GoI continues to use the 2011 census population figures to calculate the coverage under NFSA. The situation is exacerbated for migrant workers who leave their ration cards behind with their families when they migrate. Alluding to 'overflowing granaries', Sinha (2020) discusses how universalising rations is the most prudent option to arrest the food crisis. The recommendations in the SWAN reports sought to universalise

\footnotetext{
${ }^{8}$ https://scroll.in/article/959235/100-million-indians-fall-through-gaps-in-food-safety-net-economists -urge-rethink-on-covid-19-relief.
} 


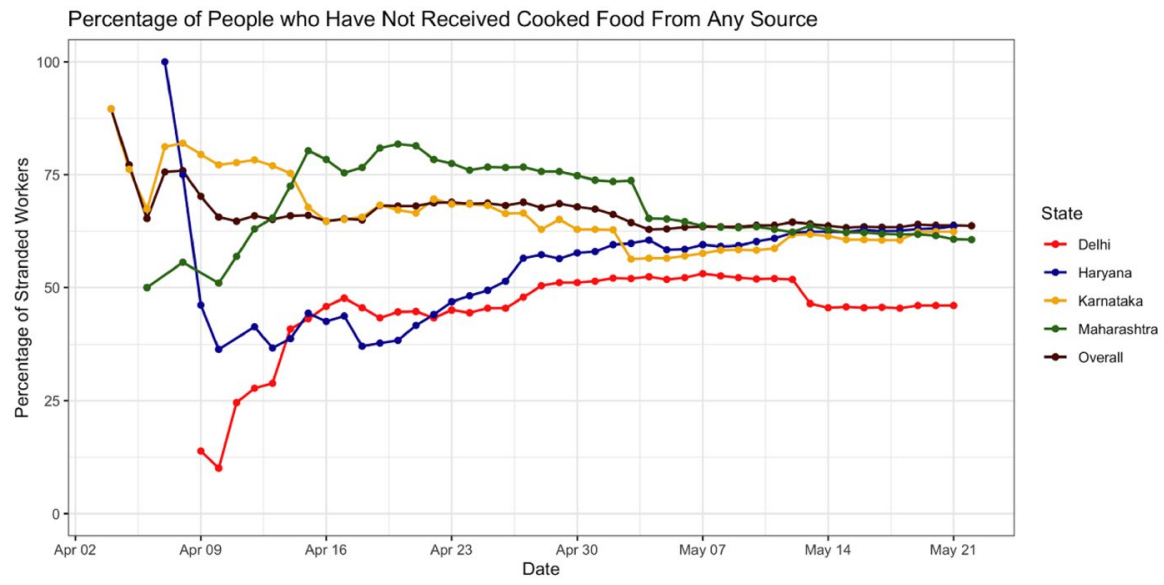

Fig. 10 Percentage of people who did not receive cooked food over time. Source: Data Collected by SWAN team

rations and provide income support of Rs 7000 per month per household for three months. We now present the hunger situation during lockdown and the inadequacy of State response.

Figure 5 depicts the number of stranded workers who responded to a question regarding whether they had received any rations at the time they reached out. The highlighted area within the graph represents the proportion of workers who had responded either 'Yes' or 'No' till that particular date. Figure 5 shows that $81.6 \%$ of workers who contacted SWAN had not received rations when they reached out to SWAN and only $18.4 \%$ of the workers had received any rations.

Figure 6 shows the average percentage of workers who did not receive rations and those who did, by looking at ten day snapshots throughout the lockdown. The red bars indicate those who did not receive rations, and the blue bars indicate those who did. The proportion of people who started receiving rations increased from the end of May, around 50 days into the lockdown.

Figure 7 depicts the distribution of the number of workers who had less than or equal to two days of rations remaining (and those that had more than two days) with them at the time they reached out. It is not cumulative. Each bar represents a single day. It is clear that the period from mid-April to mid-May is when the majority of workers who contacted SWAN had less than or equal to two days of rations remaining with them. This shows dire food insecurity throughout the lockdown. Overall, a massive $72.3 \%$ had less than or equal to two days of rations left when they reached out. This is another representation of the hunger situation during the lockdown.

Figure 8 shows access to cooked food over time, the percentage of workers has been calculated using a weekly average. From Figs. 6 and 8, we see that workers did not have consistent access to cooked food or rations throughout the lockdown. In the first two SWAN reports, the figures which showed the percentage of workers 
Table 4 Percentage of workers who were paid during lockdown

Whether worker has been paid during the lockdown

Percentage

of workers

$(n=23,891)(\%)$

\begin{tabular}{lr}
\hline No & 84 \\
Partially & 12 \\
Yes & 4 \\
\hline
\end{tabular}

Source: Data Collected by SWAN team

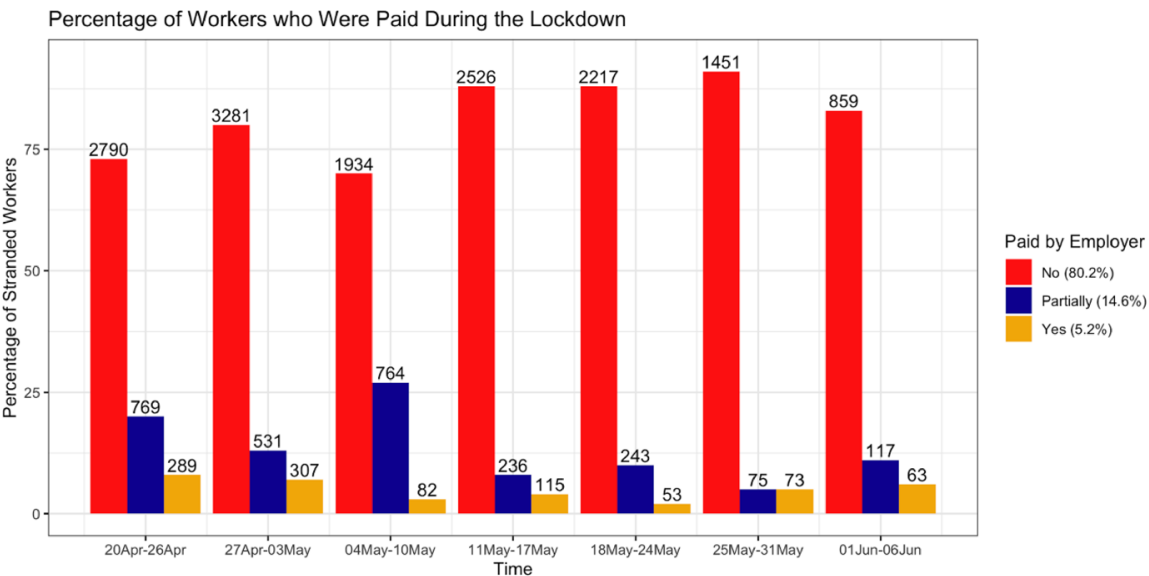

Fig. 11 Weekly snapshot of the percentage of workers who were paid during lockdown. Source: Data Collected by SWAN team

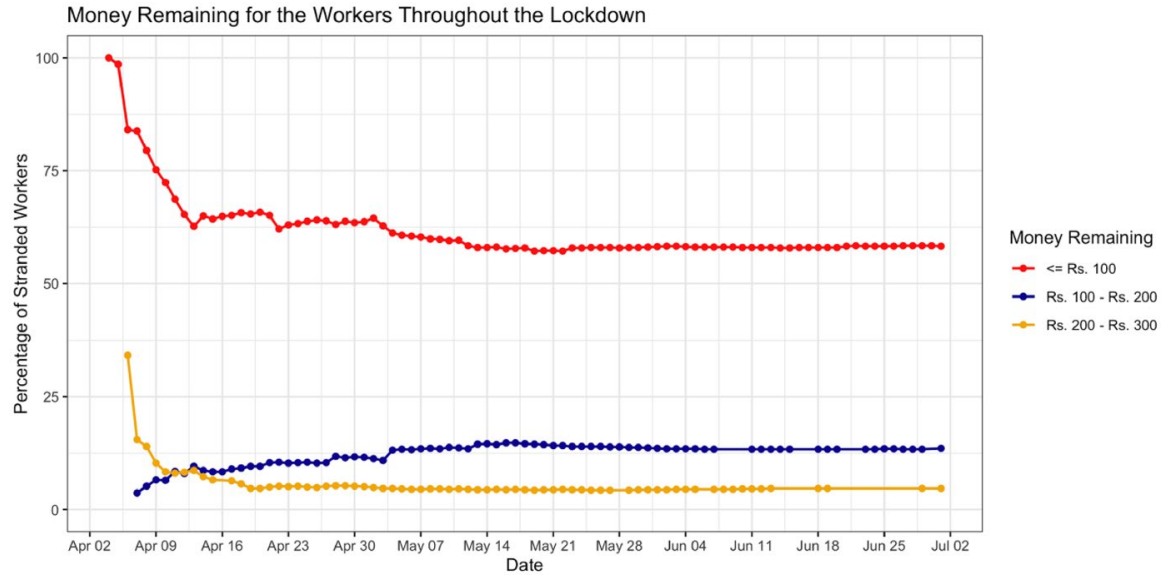

Fig. 12 Amount of money remaining over time. Source: Data Collected by SWAN team

with access to rations and cooked food were depicted from day-to-day. Hence, small changes in the percentage of workers are more apparent in the figures from the two reports. While the responses we received between May 22 and July 2 were fewer, the 
additional data shows that the situation never really improved. Recent reports indicate that three months after the announcement, only a quarter of the free foodgrain promised to migrants has been distributed..$^{9}$

Figure 9 shows the percentage of workers who have not received rations throughout the lockdown (cumulatively) as well as a breakdown of the four states from which we had the highest number of responses. As on July 2, around $81 \%$ of the workers had not received government rations. The situation was better in Karnataka compared to Maharashtra, Delhi and Haryana.

Figure 10 shows the percentage of workers who have not received cooked food throughout the lockdown (cumulatively) as well as a breakdown of the four states from which we had the highest number of responses. Overall, around two-thirds had not received cooked food till May 21. This was better in Delhi compared to the other three states.

On 16 May 2020, the Union Minister of Railways, Piyush Goyal, in his keynote address at Bennett University said, 'We have gone through the entire three months without a single person starving'. Notwithstanding the insensitivity of a Minister's comment, the above figures depicting the state of hunger during lockdown paint a completely contrary picture. The Minister's comments stand contradicted by what various surveys and testimonies (See Kesar et al. (2020) and Dvara Research (2020) indicate. More surveys on access to essential services during lockdown can be found here. ${ }^{10}$

\subsection{Wages and Employment}

Table 4 shows the percentage of workers who were paid during lockdown at the time they reached out. As can be seen, only $4 \%$ of the workers received any wages from their employers during the lockdown and $12 \%$ received partial payment. The rest $84 \%$ did not get any wages by their employers during the lockdown.

Figure 11 shows the weekly average proportion of workers who were paid by their employers during the lockdown. The tall red bars indicate those that were not paid. The non-payment of wages has been the norm throughout lockdown. Even those that were paid, in reality, corresponded to pending wage arrears from before lockdown. This illustrates the abdication of government oversight on private companies and their lack of compliance of various labour laws and the Ministry of Home Affairs directive of 29 March 2020. ${ }^{11}$

Figure 12 shows the percentage of workers who had less than or equal to Rs. 100, between Rs. 100 and Rs. 200, and between Rs. 200 and Rs. 300 remaining at various points throughout the lockdown (cumulatively). Roughly two-thirds of the people

\footnotetext{
${ }^{9}$ https://www.hindustantimes.com/india-news/only-quarter-of-80-million-migrants-got-govt-food-aid/ story-HBnQrzNtYhrrPqPn1npWvO.html.

${ }^{10}$ https://cse.azimpremjiuniversity.edu.in/covid19-analysis-of-impact-and-relief-measures/\#other_surve ys.

${ }^{11}$ https://drive.google.com/file/d/1QzAD-dUn7jOQRDWvuWOqcU3kqJObmwDH/view.
} 
had less than Rs 100 over time when they reached out to SWAN underscoring the twin terrors of hunger and lack of money.

In addition to non-payment of wages, the conditions of employment of migrant workers contributed significantly to their distress. First, was the common trend of absentee contractors. Some contractors had paid a small amount or given some provisions to tide over what they thought would be a brief period of distress and some gave nothing at all. Most contractors had either gone home or could not be contacted. Second, employers actively threatened workers with the withdrawal of accommodation and food, if they did not continue to work. Mahendra, a construction worker from Gujarat reported that despite the end of the project that they were contracted for, his group of 40 men were being forced to work, in unsafe working conditions. The employer also threatened to stop the only meal they were being provided. Another case is that of Abdul and two hundred and twelve other workers from Kolkata who were working in a factory in Bangalore. The group had reached out to an officer in Kolkata with a video of themselves, after which some government officials visited them and they received provisions from their company. Shortly after, the company called them and threatened to take serious action if they complained or revealed the name of the company. So workers who were enterprising enough to seek help through various means were threatened and beaten.

In some instances contractors themselves were left without money such as the case of Vikram who was waiting to receive Rs. 30,000 from his employer. There were also cases where some empathetic contractors did reach out to workers and paid them their full wages, and provided rations, and accommodation.

\subsection{Cash Transfers and Regulatory Frameworks of Banks}

Responding to the workers' testimonies in the first SWAN report, presented by Advocate Prashant Bhushan in the SC, the Solicitor General, Tushar Mehta remarked 'Who told Mr Bhushan that no one is getting anything? There are direct benefit transfer schemes'.

According to our data, only 348 people received the promised Rs.500 in their Jan Dhan Yojana (JDY) accounts. Other surveys assessing the JDY cash transfer scheme do not paint a glowing picture either (Kejriwal 2020). Moreover, a lower share of migrant households received this transfer compared to non-migrant households. And, a lower percentage of Muslim households received this cash transfer compared to Hindu households (Kesar et al. 2020).

Access to cash once transferred was also an issue. Many banks had regulations that account holders must maintain a minimum balance failing which the accounts are frozen. Consequently, money transferred is automatically deducted as a penalty for not maintaining the minimum balance. These regulations are particularly harsh for the vulnerable who tend to have low savings. In general, these cases are harder to detect and resolve adding another layer of hardship. Some testimonies are presented in SWAN (2020a, b).

The migrant worker crisis has also stymied principles of federalism and exposed the fractures of the Bharatiya Janata Party's 'one nation' narrative. As Dhorajiwala 
and Narayanan (2020) argue, even in such times of crisis the poorer states such as Bihar and Jharkhand have attempted to seek out 'their people' stuck in richer states with a one-time app-based cash transfers. Neither the GoI nor the richer states have offered any income support.

\subsection{Difficult Journeys Home}

A unique and another manufactured malady was the travel-related chaos and ensuing tragedies. SWAN's third report (SWAN 2020c) was dedicated to this issue. We present a brief summary here.

We conducted an Interactive Voice Response (IVR) survey (in collaboration with https://gramvaani.org/). Calls were randomly made to 1963 workers who had been provided some assistance through SWAN. ${ }^{12}$ By the end of June, 67\% (of 1963) migrants were still stuck in the same place since the lockdown was announced. Of those who were stuck, 55\% (out of 1166) wanted to go home immediately. For the same question, in April, only 33\% wanted to leave immediately after the second phase of lockdown. This was hard evidence in the face of GoI's claims that most migrants had returned home and that Shramik trains were no longer needed. The desire to return home was not being driven by 'sentiment' alone as the narrative whipped up by some media houses and officials suggested. 75\% (of 1124) of the stranded migrants did not have any employment. Of those who decided to travel, $44 \%$ took buses and $39 \%$ managed to get on a Shramik special. 11\% took trucks, lorries and other such modes of transport, while $6 \%$ made the perilous journey on foot. These journeys were arduous with difficulties such as long waits at police and railway stations without any information on train schedules, high costs and bribes, poor facilities on trains including lack of food and water, poor transport arrangements to and from railway stations. Nearly 100 people died on board Shramik special trains or within railway premises, en route to their home states. ${ }^{13}$ In fact even though the SC had issued an interim order on May 28 that migrants will not have to pay for travel, more than $85 \%$ of the migrant workers who had returned home or were in transit had to incur high costs for this journey.

\section{Severity of Vulnerability During the Lockdown}

The volunteers' comments strongly indicate the various layers of distress, often overlapping, that aggravated the vulnerability of the stranded workers and their families. For those stranded in containment zones, access to rations, cooked food and ATMs were hard due to severe police restrictions. In some cases, they were badly harassed by the police, pushing them further into situations of extreme starvation and without

\footnotetext{
12 Here we assume that the respondent's response is valid only for that person and does not reflect the thought of the group.

13 https://indianexpress.com/article/india/110-migrants-died-on-railway-premises-when-shramik-specialtrains-were-run-6498557/.
} 


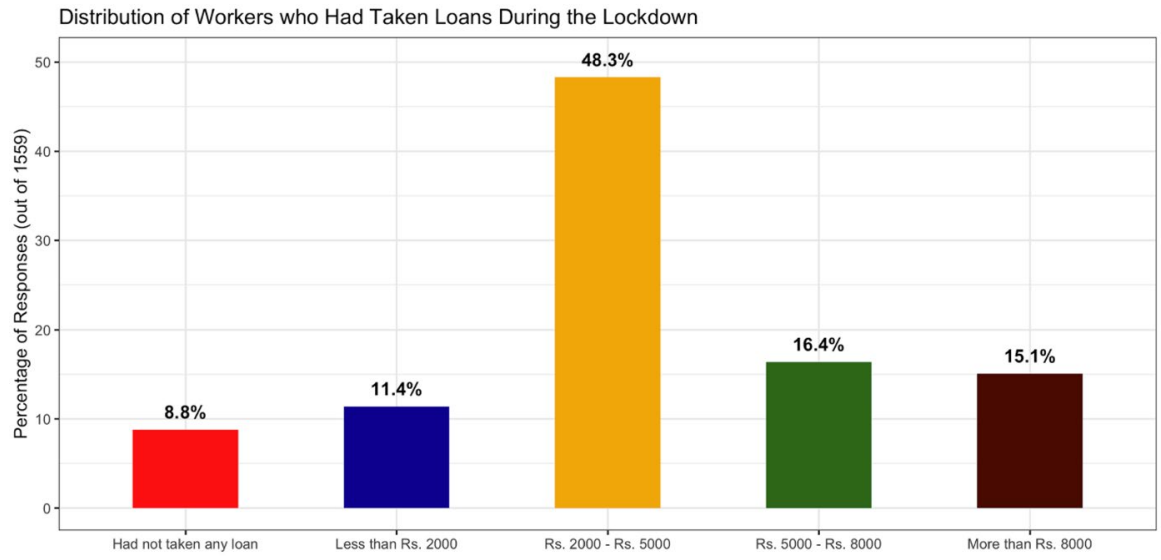

Fig. 13 Percentage of people who had to take loans (IVR survey). Source: Data Collected by SWAN team

any safety net or legal support against police brutality. With no government rations/ cooked food reaching them, the workers were mostly dependent either on generous neighbours or on the support of CSOs provided the CSO volunteers were allowed to enter the containment zones.

For instance, Alam Khan, a daily wage labourer staying with his family in Gurugram, had not eaten for three days while ensuring that his family, which included an ailing child suffering from pneumonia, had eaten. In another case, there were a group of 13 daily wage labourers from Bihar who were stranded in a containment zone in Delhi. Food had been inaccessible for them, and they had been surviving on water for days. Moreover, while government run canteens and distribution centres provided some relief, they continued to be male-dominated spaces. This made it difficult for women to access them.

Moreover, some workers required immediate medical assistance. Amount of cash available among workers also became a marker of urgency. Many workers had no money for basic needs like milk, vegetables, oil, water, gas, phone recharge, etc.

We elaborate on some factors that added to their vulnerability in each subsection below. They are: (a) Debts, (b) Women's vulnerability and abuse, (c) Children, (d) Access to healthcare, (e) Mental health. We emphasise that these are neither mutually exclusive nor exhaustive. Several workers straddled each of these dimensions of vulnerability and more. Owing to space limitations, we present only those that were most pronounced.

\subsection{Debts}

Many workers were forced to survive by borrowing from friends, relatives and shops. This pushed them into a cycle of indebtedness. For instance, when Arun Kumar, a migrant from Bihar worked in a textile factory in Ludhiana, Punjab, reached out to SWAN in June, he had already taken Rs 14,000 worth of rations on 
credit over three months from a local shopkeeper. In addition, he had to also pay his monthly house rent of Rs 10,000.

Figure 13 shows the distribution of those workers who had to take loans during lockdown. Out of 1559 people who responded to this question in the IVR survey, 48\% had taken loans between Rs 2000 and Rs 5000 during this period. A whopping $31 \%$ had taken loans of more than Rs 5000.

\subsection{Women's Vulnerability \& Exploitation}

Women workers were particularly impacted adversely during lockdown. In fact, even those remaining in rural areas faced multiple challenges. Pregnant women require regular nutritional interventions with routine maternal and foetal assessment for the well-being of the mother and the child (World Health Organization 2016). Pregnant women barely had access to the required nutrition and safe, hygienic medical care or prenatal checkups. Most local clinics and Public Health Centres (PHCs) were shut. Some women had expressed fear of visiting government hospitals due to fear of contracting coronavirus, and private hospitals were expensive. With no money for ultrasounds, scans and other needs, pregnant women had to miss their routine checkups. For instance, Praveen Kumar and his family moved to Mumbai from Uttar Pradesh. His wife, 8 months pregnant, had not been able to get a scan since the beginning of the lockdown. Praveen, the sole breadwinner, earned Rs 350 daily before the lockdown but had not received any payment since. New mothers with caesarean delivery requiring special attention were not able to get proper meals and medicines either.

Domestic violence had hit a 10-year high since lockdown according to the National Commission of Women. ${ }^{14}$ Some women were stuck with their abusers, often disguised as family members, with no escape. Those who reached out to us expressed that they were under the constant threat of physical, emotional and psychological abuse. Urmila Devi was a widow staying in Patna, Bihar, with her in-laws and four daughters. Urmila and her daughters did not get sufficient food and were continuously subjected to verbal abuse by her in-laws. She kept cursing herself for having female children, and she wanted to get away from her daughters by getting them married as soon as possible.

Many women workers were stranded with alcoholic husbands. In some cases, the inebriated husbands disrupted relief efforts. For such cases, volunteers had to be more sensitive and cautious to make sure that the required monetary help would reach the woman. There were also calls from women whose husbands abandoned their families. Fatima was stranded in Mumbai with her 8-month-old child. She only had Rs 13 left with her. Her alcoholic husband had not been home for 3-4 days. In another instance, Lakshmi from Mumbai was given eviction threats by her landlord. Her husband had impulsively left her and the children, and she was struggling to pay the monthly rent of Rs 1500 . What further exacerbated the situation of women

\footnotetext{
14 https://www.thehindu.com/data/data-domestic-violence-complaints-at-a-10-year-high-during-covid -19-lockdown/article31885001.ece.
} 


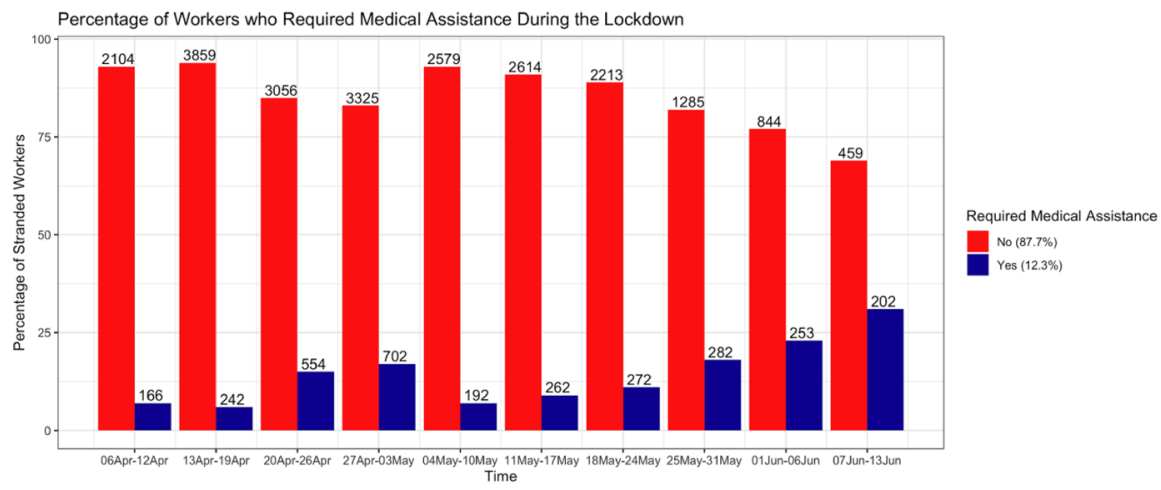

Fig. 14 Percentage of workers who required medical assistance. Source: Data Collected by SWAN team

migrant workers was the poor access and enrolment in various pre-existing welfare schemes.

According to a recent report by Action Aid Association (India) (2020), 79\% of women workers were rendered unemployed by mid-May, compared to $75 \%$ of men. Moreover, there has been a surge in women's unpaid labour in the household. This will further push women out of the workforce. By early May 2020, some factories and companies began reopening their operations. While many workers wanted to return home, many had to stay back and earn as they ran out of savings. Sensing this catchment of labour, many employers and contractors began discriminating against women. Women workers, in a few cases, were told that they would not be called back for work. By consciously choosing male workers over female workers, the authorities perpetuated the patriarchal norms known to exist in the capitalistic system-wherein, female workers were seen as being less productive and were treated only as a contingency pool of labour. ${ }^{15}$ For instance, quoting her labour contractor, Shila Devi, a migrant worker employed in a garment factory in Gurugram, Haryana, said, 'The contractor has told us that women will not be called to work. Only men would'.

A horrific case of two Adivasi women trafficked from Dumka district, Jharkhand to Bangalore via Delhi had come to our attention ${ }^{16}$ (SWAN 2020c). This ordeal is one of many experiences of humiliation that women workers have undergone for decades. This also shows that lack of the government oversight of private firms opens many avenues of exploitation.

\footnotetext{
15 (i) https://www.epw.in/engage/article/different-workplaces-similar-exclusions (ii) https://www.thena tion.com/article/archive/is-there-room-for-women-workers-under-capitalism/.

16 https://www.thehindu.com/news/cities/bangalore/women-labourers-from-jharkhand-face-ordeal-infactory/article31680957.ece.
} 


\subsection{Presence of Children}

While rations and cooked food provided by the government, in some measures, could support the adults, milk was not available in such government-run centres. Pooja Devi, from Bihar, was stranded in Punjab with her family. She mentioned that she had to ask her children to eat some biscuits for dinner and sleep. Families with children were also hassled as they had to face challenges for getting food from the distribution centres that were marred by long queues. But they still had to go with children because the quantity of food was dependent on the number of people in the queue.

Government schools were largely shut, and many private schools migrated to online classes. However, children of migrants have paid a heavy price in this. Their education has been disrupted, and those in private schools that have migrated to online classes have had difficulty paying the fees. Moreover, many were unable to recharge their phones (for online classes) due to lack of money. So education of millions of children has been jeopardised since there was no plan in place for that.

\subsection{Access to Healthcare}

Overall, 3204 people who reached out to SWAN required medical assistance. Of these, 1588 were women and children. While COVID-19 was given priority, other diseases and ailments received scant attention in hospitals. The poor tend to live in unhygienic conditions and were hit the hardest. As OPDs and general wards in government hospitals were non-functional or were converted into emergency wards for COVID-19 patients, several workers with chronic illnesses like diabetes, heart diseases, tuberculosis and other injuries such as wounds, burns and fractures either chose not to get any treatment or had to visit expensive private hospitals. For instance, Indu Devi from Bihar, stranded in Ludhiana, Punjab, with her family had an epileptic child. The family had to reduce the daily dosage of medicines for her son, hoping it would last longer. Consequently, her son had an epileptic seizure. In many instances, workers had to make a potentially life-threatening choice between buying medicines and having a meal. Figure 14 shows the percentage of people requiring medical assistance over weekly snapshots through the lockdown.

Due to lack of potable water, many reported severe gastrointestinal problems. This was further intensified due to shortage of money to buy fuel. For example, Nitu Devi, a domestic worker in Delhi, had a recurring stomach ache. She had no money to buy cooking gas to boil water. Further, many migrant workers had moved to major cities like Delhi and Mumbai to get medical treatment a few months before the lockdown, leaving them stranded without support. 


\subsection{Mental Health}

The extent of food insecurity, loss of livelihoods and lack of medical care for migrants have been widely discussed, and rightly so. However, anxiety, fear, depression and uncertainties concerning their life have received less attention. In particular, being in a cramped space with no work place and constant uncertainty surrounding food spawned a mental health crisis.

The government established a helpline number to provide tele-counselling to those migrants who had not had provisions for a month. Gol's attempts at technocratic solutions to deal with the immense mental trauma that migrants experienced appear to be a cruel joke. By avoiding the socio-political context of the migrant crisis, the government exacerbated the mental health trauma of the workers. In situations like this, the 'simplistic psychiatric diagnostic' categorisation of migrant workers' suffering undervalued the extent of the human rights violation of the workers (Kottai 2020).

Workers' voices resounded with a strong aversion towards urban spaces. A worker at the brink of starvation exclaimed, 'I will never return to the city'. Several workers would break down on calls in helplessness. Some felt guilty of reaching out for help as they felt it impinged on their dignity to seek help. Mohammed Imraan, the sole earning member of his family, used to work as a cook in a Chinese restaurant in Delhi and had a family of eight to feed. After about two months of being stuck in Delhi, he and his family managed to reach back to Jharkhand. While talking to our volunteer, he broke down: 'I am the eldest and have 8 family members to support. I have no work. I am very anxious. Sometimes I feel like committing suicide but some have given me strength. I have an old mother and children to support'.

Arshad worked delivering pizzas in Gurugram. Upon learning that some of his colleagues were partially paid, he approached his employer to ask about his payments. His employer not only dismissed him but also asked Arshad not to contact him again. After losing his employment, his tenement in Delhi was destroyed recently by the Delhi government. The reasons pertain to some old litigation on the land where his tenement was located. A few days later, his temporary encampment got flooded and he lost a lot of belongings. In utter agony, he said 'Everything is destroyed. I see no meaning in living anymore'.

The trauma inflicted upon the migrant workers due to inadequate measures and the apathetic response of the government very much required wider understanding and professional intervention. As volunteers of SWAN, we were not equipped to deal with mental health issues.

\section{Discussion}

The repercussions of lockdown will be felt for months if not years and as the migrant worker crisis has revealed, India's social security system is not up to the task with its current reach and budget outlays. Destroyed livelihoods and food insecurity coupled with a crippled public health system is an urgent call for an expansion and increase in public spending on social security. The current set of relief measures which has 
been touted to be equivalent to an inflated figure of $10 \%$ of the GDP is just a fraction of what it needs to be (Ghosh 2020; Ray and Subramanian 2020). The meagreness of the relief package combined with the "legitimised" opacity of the PM-CARES fund only further validates India's fiscal response to the COVID crisis as one of the weakest in the world. We end with a few proposals.

To start with, the two pillars of India's relief response, NREGA and PDS need to be bolstered more than ever before. While the NFSA certainly increased the scope of the PDS by further expanding coverage and subsidising rations more, it was not able to alleviate the acute food distress of migrant workers who remained outside its reach. One of the key recommendations made in the SWAN reports was to double PDS rations for a period of 3 months and to home-deliver these rations free of charge (SWAN 2020a). Despite the delayed announcement to this effect, most migrant workers who left for their homes or who were in transit (and now may even be back in the cities they fled from) still have not received the promised grain. In addition to the demand to universalise PDS for at least six months, numerous economists, activists, and SWAN have consistently advocated for a combination of food and cash instead of binaries of food or cash. While recommendations regarding rations were partially met, the critical recommendation regarding income support is yet to be considered.

While NREGA has always been vital, it has assumed renewed significance in light of the unemployment crisis induced by the lockdown. With millions of migrants returning home and the rural economy stagnating, NREGA has become a lifeline. With an unprecedented budget allocation of Rs 1 trillion for NREGA, the government too has validated NREGA's importance and reliability during this time of crisis. 8.5 million new job cards have been made since April 2020 and 58 million households employed in 2020 so far which is considerably higher than the same period in the last three years. These figures indicate the massive potential of NREGA which needs to be tapped into and enhanced to a 200 day per person employment guarantee.

Despite the human tragedy that unfolded, a disturbing development was the suspension of labour laws in certain states in a bid to restart the economy. Responding to large-scale distress of the working class requires an urgent strengthening not dilution of labour laws. We need to reconfigure our society and economy by placing workers' rights and dignity at the centre of public discourse, in keeping with the values of the Indian constitution. The Parliamentary Standing Committee on Labour has taken note of the migrant worker crisis in its recent report on the Social Security Code and makes recommendations for creating a national database of workers, especially migrant workers for interstate portability of benefits and also calls for setting up a welfare fund. There needs to be wider consultation with various workers, trade unions and other CSOs prior to any promulgation in this regard.

The need for a comprehensive evaluation and implementation of social protection measures is critical. In 2007, The National Commission for Enterprises in the Unorganised Sector (NCEUS) demonstrated the appalling extent to which basic safety norms and minimum wage regulations were being violated and made several progressive recommendations (Srivastava 2012). However, they continue to be ignored. 
Interestingly, despite being the reason for lockdown, COVID barely featured in the issues brought up by workers. Food, money, employment and transportation overshadowed any health issues that workers faced. Out of 3904 comments from workers with specific requests and descriptions of their situations, only $12 \mathrm{com}$ ments actually featured the word "Corona" or "COVID". Most of these were in the context of not being able to travel back home due to lockdown restrictions.

While the State's responses were inadequate and callous, many individuals and CSOs, despite restricted mobility, showed courage and demonstrated solidarity with workers. This gives a glimmer of hope. However, there are limitations to how much CSOs can achieve. There is a lot to be desired as the struggle for justice for workers is far from over. Instead of abdicating its duties and denying the issue exists as it did in the first Parliament session held after the lockdown, the Indian government must act with conscience, transparency and accountability to ensure workers are guaranteed their constitutional rights to equality, justice and a life of dignity.

\section{References}

Action Aid Association (India). 2020. Workers in the Time of COVID-19. https://www.actionaidindia. org/wp-content/uploads/2020/08/Workers-in-the-time-of-Covid-19_ebook1.pdf.

Deaton, A., and J. Drèze. 2002. Poverty and Inequality in India: A Re-Examination. Economic \& Political Weekly 37 (36): 3729-3748.

Dhorajiwala, S., and R. Narayanan. 2020. Locked Down in Distress. The Indian Express, May 9, 2020. https://indianexpress.com/article/opinion/locked-down-in-distress-6400569/.

Drèze, J., and A. Sen. 2013. An Uncertain Glory: India and Its Contradictions, 1st ed. Delhi: Allen Lane, Penguin Group.

Dvara Research. 2020. CoVID-19 Impact on Daily Life. https://www.dvara.com/research/wp-content/ uploads/2020/08/COVID-19-Impact-on-Daily-Life-Survey.pdf.

Gaikwad, N., and G. Nellis. 2020. Do Politicians Discriminate Against Internal Migrants? Evidence from Nationwide Field Experiments in India. American Journal of Political Science 1: 1. https://doi. org/10.1111/ajps.12548.

Ghosh, J. 2020. A Critique of the Indian Government's Response to the COVID-19 Pandemic. Journal of Industrial and Business Economics 47: 519-530. https://doi.org/10.1007/s40812-020-00170-x.

Government of India, Ministry of Statistics and Programme Implementation. 2020. Annual Report: Periodic Labour Force Survey (July 2018-June 2019). New Delhi. http://www.mospi.gov.in/sites/defau 1t/files/publication_reports/Annual_Report_PLFS_2018_19_HL.pdf.

Gramvaani. 2020a. Mobile Vaani: Survey of Resident Workers. https://drive.google.com/file/d/1GNiT smOJP9W4J-hdgZCNvHa7GgMggnSh/view.

Gramvaani. 2020b. Mobile Vaani: Survey of Migrant Workers. https://drive.google.com/file/d/1sCYW aow14pLN0osg8PMRH1PeoepN8-h-/view.

Hale, T., N. Angrist, B. Kira, A. Petherick, T. Phillips, and S. Webster. 2020. Variation in Government Responses to COVID-19. Blavatnik School of Government Working Paper, May. https://www.bsg. ox.ac.uk/sites/default/files/2020-05/BSG-WP-2020-032-v6.0.pdf.

Himanshu. 2018. India Inequality Report 2018: Widening Gaps. Oxfam India. https://www.oxfamindia .org/sites/default/files/WideningGaps_IndiaInequalityReport2018.pdf.

Jayadev, A., S. Motiram, and V. Vakulabharanam. 2007. Patterns of Wealth Disparities in India during the Liberalisation Era. Economic \& Political Weekly 42 (38): 3853-3863.

Jha, S. 2019. Consumer Spend Sees First Fall in 4 Decades on Weak Rural Demand: NSO Data. Business Standard, November 15, 2019. https://www.business-standard.com/article/economy-policy/consu mer-spend-sees-first-fall-in-4-decades-on-weak-rural-demand-nso-data-119111401975_1.html. 
Kapoor, R. 2019. Understanding India's Jobs Challenge. The Indiaforum, September 10, 2019. https:// www.theindiaforum.in/article/what-periodic-labour-force-survey-telling-us-about-employment-andunemployment-india.

Kapoor, R. 2020. The Unequal Effects of the Covid-19 Crisis on the Labour Market. The Indiaforum, August 7, 2020. The Unequal Effects of the Covid-19 Crisis on the Labour Market.

Katakam, A. 2020. The SWAN Reports: Records of Heroism by Migrant Workers. Frontline, August 14, 2020. https://frontline.thehindu.com/the-nation/records-of-heroism/article32186017.ece.

Kejriwal, S. 2020. Is Jan Dhan Money Actually Reaching People? India Development Review, May 6, 2020. https://idronline.org/is-jan-dhan-money-actually-reaching-people/.

Kesar, S., R. Abraham, R. Lahoti, P. Nath, and A. Basole. 2020. Pandemic, Informality, and Vulnerability: Impact of COVID-19 on Livelihoods in India. Working Paper. Centre for Sustainable Employment, Azim Premji University, June. https://doi.org/10.1002/mpr.329.

Kottai, S.R. 2020. Migrant Workers and the Politics of Mental Health. Economic \& Political Weekly 55 (31): 39-45.

Nath, P., and A. Basole. 2020. Did Employment Rise or Fall in India between 2011 and 2017? Estimating Absolute Changes in the Workforce. Working Paper. https://cse.azimpremjiuniversity.edu.in/wpcontent/uploads/2020/08/Nath_Basole_Employment_Trends_2011-2017_August_2020.pdf.

NCEUS. 2008. Contribution of the Unorganised Sector to GDP Report of the Sub Committee of a NCEUS Task Force. New Delhi.

Ray, D., and S. Subramanian. 2020. India's Lockdown: An Interim Report. NBER Working Paper No. 27282 https://www.nber.org/papers/w27282.pdf.

Sen, S. 2020. Modi's Government Has Botched Its Response to India's Pandemic. Jacobinmag, April 25, 2020. https://www.jacobinmag.com/2020/04/india-narendra-modi-pandemic-coronavirus-bjp?.

Sen, A., and Himanshu. 2004. Poverty and Inequality in India-II. Economic \& Political Weekly 39 (39): 4361-4375.

Sharma, K. 2017. India Has 139 Million Internal Migrants. They Must Not Be Forgotten. World Economic Forum, October 1, 2017. https://www.weforum.org/agenda/2017/10/india-has-139-millioninternal-migrants-we-must-not-forget-them/.

Sinha, D. 2020. Grain Aplenty and the Crisis of Hunger: On Universal Public Distribution System. The Hindu, June 30, 2020. https:/www.thehindu.com/opinion/op-ed/grain-aplenty-and-the-crisis-ofhunger/article31948530.ece.

Srivastava, R. 2011. Labour Migration in India: Recent Trends, Patterns and Policy Issues. Indian Journal of Labour Economics 54 (3): 411-440.

Srivastava, R. 2012. Social Protection for Workers in India: Struggling for Basic Rights under Increasing Labour Market Flexibility. Indian Journal of Labour Economics 55 (2): 177-199.

State of Working India. 2018. State of Working India 2018. https://cse.azimpremjiuniversity.edu.in/wpcontent/uploads/2019/02/State_of_Working_India_2018-1.pdf.

Subramanian, S. 2019. What Is Happening to Rural Welfare, Poverty, and Inequality in India? The Indiaforum, December 6. https://www.theindiaforum.in/article/what-happened-rural-welfare-povertyand-inequality-india-between-2011-12-and-2017-18.

SWAN. 2020a. 21 Days and Counting: COVID-19 Lockdown, Migrant Workers, and the Inadequacy of Welfare Measures in India. http://publications.azimpremjifoundation.org/2272/.

SWAN. 2020b. 32 Days and Counting. https://watson.brown.edu/southasia/news/2020/32-days-and-count ing-second-report-swan-migrant-worker-distress-and-extended-lockdown.

SWAN. 2020c. To Leave or Not to Leave: Lockdown, Migrant Workers, and Their Journeys Home: http:// strandedworkers.in/mdocuments-library/.

Thampi, A., and I. Anand. 2019. Most Regular Jobs in India Don't Pay Well: PLFS. Livemint, August 6, 2019. https://www.livemint.com/politics/policy/most-regular-jobs-in-india-don-t-pay-wellplfs-1565075309032.html.

Vakulabharanam, V., and S. Motiram. 2012. Understanding Poverty and Inequality in Urban India since Reforms Bringing Quantitative and Qualitative Approaches Together. Economic \& Political Weekly 47 (47-48): 44-52.

World Health Organization. 2016. WHO Recommendations on Antenatal Care for a Positive Pregnancy Experience. https://www.who.int/reproductivehealth/publications/maternal_perinatal_health/ancpositive-pregnancy-experience/en/. 
Publisher's Note Springer Nature remains neutral with regard to jurisdictional claims in published maps and institutional affiliations.

\section{Affiliations}

Anindita Adhikari ${ }^{1}$ - Navmee Goregaonkar ${ }^{2}$ - Rajendran Narayanan ${ }^{3,4}$. Nishant Panicker ${ }^{3}$. Nithya Ramamoorthy ${ }^{5}$

Anindita Adhikari

aninditaadhikari@gmail.com

Navmee Goregaonkar

navmee06@gmail.com

Nishant Panicker

nishant.panicker16ug@apu.edu.in

Nithya Ramamoorthy

nithya.r16ug@apu.edu.in

1 Brown University, Providence, USA

2 St. Xavier's College (Autonomous), Mumbai, India

3 Azim Premji University, Bangalore, India

4 LibTech India, Bangalore, India

5 Pudiyador, Chennai, India 